\title{
Retratos do Brasil: uma coleção do Rockefeller Archive Center
}

\author{
Images of Brazil: a Rockefeller \\ Archive Center collection
}

\author{
Aline Lopes de Lacerda \\ Pesquisadora do Departamento de Arquivo e Documentação da \\ Casa de Oswaldo Cruz/Fiocruz \\ lacerda@coc.fiocruz.br
}

\begin{abstract}
Este artigo objetiva apresentar uma descrição comentada da coleção fotográfica sobre o Brasil pertencente aos arquivos da Fundação Rockefeller nos Estados Unidos, o Rockefeller Archive Center. Traz informações sobre a origem de tal documentação, bem como sobre as formas de sua acumulação, tendo em vista compreender o contexto de produção daqueles documentos visuais. Tais documentos dizem respeito às relações entre a Fundação Rockefeller e organismos brasileiros voltados para o combate a doenças como a febre amarela, a malária e a ancilostomíase entre os anos 1920 e 1940.

PALAVRAS-CHAVE: fotografia, Fundação Rockefeller, saúde pública, arquivo fotográfico, febre amarela, malária, ancilostomíase, sanitarismo.
\end{abstract}

This article describes and comments on the collection of photographs of Brazil that belongs to the Rockefeller Foundation archives (Rockefeller Archive Center) in the United States. It also contains information about the origin of such documents and the way they were collected, as well as analyzes the context in which these visual documents were produced. They record the relationship between Rockefeller Foundation and Brazilian institutions engaged in the combat against yellow fever, malaria and ancyclostomiasis from 1920 to 1940 .

KEYWORDS: photography, Rockefeller Foundation, public health, photographic files, yellow fever, malaria, ancyclostomiasis, sanitation

\begin{abstract}
A longa parceria entre norte-americanos e brasileiros no combate a doenças endêmicas, especialmente a febre amarela, na primeira metade do século XX, constitui um dos capítulos mais marcantes na história da saúde pública brasileira. Os primeiros contatos entre médicos da Fundação Rockefeller e membros do governo brasileiro aconteceram a partir de 1916, com a vinda de comissões norte-americanas para avaliação do cenário de saúde nacional. Mas data do ano de 1923 o estabelecimento de convênio entre o governo brasileiro e a fundação, que fez uma dotação de recursos financeiros e garantiu a cooperação médico-sanitária e educacional para a implementação de programas
\end{abstract}


de erradicação das endemias, um problema grave que afetava todo o país, sobretudo as regiões do interior, onde os trabalhos concentraramse no combate à febre amarela e, mais tarde, à malária. Inicialmente atuando como coadjuvante junto aos serviços estaduais e municipais no combate a doenças como ancilostomíase, a Fundação Rockefeller ampliou sobremaneira sua participação e influência na área governamental de saúde pública, sobretudo a partir da década de 1930, combatendo a febre amarela. Essa doença foi considerada à época o maior desafio para a equipe norte-americana e contou, durante os anos 1930 e 1940, com um aparato organizacional ímpar na história de combate sistemático a uma endemia.

Com uma estratégia definida, que tinha como objetivo o completo extermínio do então considerado único vetor da doença — o mosquito Aedes aegypti -, aos poucos, e por força das circunstâncias - a verificação comprovada da existência da forma silvestre da doença , a fundação intensificou as atividades de pesquisa em laboratório visando ao aperfeiçoamento de uma vacina eficaz contra a moléstia. Esse processo foi simultâneo a uma associação da Fundação Rockefeller com organismos governamentais criados para atuar nesse mesmo cenário - como o Serviço Nacional de Febre Amarela (SNFA), o Serviço de Malária do Nordeste (SMNE) - o que concorreu para ampliar o alcance de suas ações e, ao mesmo tempo, propiciar uma troca de experiências e influências entre as instituições brasileiras e a norte-americana.

A conseqüência mais marcante dessa parceria foi a incorporação de um modelo de campanha de saúde pública no Brasil que iria marcar a área muitos anos após a saída formal da Rockefeller do país. A partir da década de 1940, a instituição norte-americana paulatinamente retirouse e transferiu o controle das campanhas e de suas pesquisas para o SNFA, cujo laboratório de produção da vacina acabou sendo incorporado, em 1950, ao Instituto Oswaldo Cruz (IOC), atualmente uma das unidades da Fundação Oswaldo Cruz (Fiocruz).

Esses anos de trabalho de pesquisa dentro e fora dos laboratórios foram registrados de diversas formas. Hoje, podem ser recuperados pela pesquisa a dois arquivos institucionais que guardam documentos sobre esse episódio de cooperação entre Brasil e Estados Unidos. Tratase da documentação sob a guarda da Casa de Oswaldo Cruz/Fiocruz, no Brasil, e da documentação sob a guarda do Rockefeller Archive Center (RAC), nos Estados Unidos. Este artigo é fruto de pesquisa nos arquivos depositados no RAC, notadamente a coleção de fotografias sobre o Brasil, cujas características serão comentadas a seguir.

\section{As coleções fotográficas pertencentes ao RAC}

As imagens sobre o Brasil encontradas no arquivo da Fundação Rockefeller fazem parte das coleções de fotografias que, reunidas, formam 
o acervo visual sob a guarda do RAC. ${ }^{1}$ Essas coleções são provenientes dos arquivos (The Rockefeller University, The Rockefeller Foundation, Rockefeller Brothers Fund e The Rockefeller Family) e das coleções de manuscritos (divididas segundo organizações e indivíduos) ali depositadas e, nesse sentido, guardam estreita relação com toda a documentação, constituindo um conjunto orgânico com informações, em muitos casos, complementares. Tanto as organizações quanto os indivíduos de cuja documentação as imagens são parte integrante estão relacionados com as atividades das organizações filantrópicas que, desde o início do século XX, tiveram atuação marcante nas áreas de medicina, ciências biológicas e físicas, agricultura, saúde pública, educação, humanidades e ciências sociais.

O fundo Fundação Rockefeller - o maior em termos de volume de documentos - possui outros conjuntos de imagens além das fotos sobre o Brasil, perfazendo um total de cerca de cem mil itens, entre fotografias monocromáticas e coloridas, negativos, álbuns e slides produzidos no período de 1913 a 1966. Trata-se de um conjunto de imagens extremamente rico sobre as atividades de todos os 'braços' da fundação dentro e fora dos Estados Unidos. ${ }^{2}$ Grande parte da coleção reflete o interesse inicial da instituição pelas ciências médicas, doenças tropicais e saúde pública, tanto em âmbito nacional quanto internacional.

Do ponto de vista da atuação da Rockefeller fora do território norteamericano, a coleção é muito significativa, pois traz imagens dos trabalhos realizados em vários países do Terceiro Mundo, mostrando doenças prevalecentes e atividades de assistência médica, assim como o cenário local, a vida social e as condições de existência das populações daqueles países. A maior parte dessas imagens são anteriores a 1940. As fotografias encontram-se arquivadas por país e subdivididas em categorias temáticas gerais.

Os assuntos que concentram o maior número de registros visuais são os relativos às ciências médicas — escolas de medicina, laboratórios, hospitais, pesquisas com animais, produção de vacinas-, enfermagem — formação de enfermeiras, incluindo suas atividades práticas - e saúde pública — exposições, demonstrações e paradas, campanhas de leite, laboratórios e clínicas de saúde pública, aulas de nutrição, inoculação para febre tifóide, instalações de latrinas, campanhas de higiene pessoal.

Além desses assuntos mais gerais, algumas doenças são temas presentes, como ancilostomíase - pacientes antes e após o tratamento, exposições, clínicas rurais, mobiliário de laboratório e equipamentos,

\footnotetext{
${ }^{1}$ As informações subseqüentes foram extraídas de Photographic collections in the Rockefeller Archive Center, uma publicação do RAC, de 1986. Na época, somente os registros visuais processados foram ali incluídos.

${ }^{2}$ Como a China Medical Board, International Health Commission/Board e Rockefeller Sanitary Commission for the Erradication of Hookworm Disease.
} 
instalações de latrinas e condições de vida da população afetada; malária — tentativas de controle (destruição do mosquito), exame de pacientes, distribuição de quinina; febre amarela - tentativas de controle, captura de mosquitos, exame e tratamento de pacientes; tuberculose - condições ambientais gerais, exposições e clínicas de tratamento.

Ainda há imagens que documentam as pesquisas em desenvolvimento, como é o caso da então incipiente área de virologia. Por último, estão documentadas as atividades que resultaram da atuação da Fundação Rockefeller em outras áreas do conhecimento, tais como humanidades - exposição de artes, aulas de teatro e música, estúdios de rádio e televisão, programas de língua inglesa e estrangeira, programas de história da América, Ásia e história islâmica, coleções de museus e bibliotecas e programas de conservação; ciências sociais - computação, economia, estudos internacionais e de população; ciências naturais - incremento em pesquisa e laboratórios em física, biologia, química, microbiologia, genética, pesquisa atômica, astronomia e outros campos de estudos científicos; agricultura maquinaria agrícola, controle de pragas e de doenças em plantas, novos métodos de colheita.

\section{O Brasil nas coleções fotográficas do RAC}

Integra o conjunto de registros visuais do fundo Fundação Rockefeller, depositado no RAC, uma série de imagens sobre o Brasil, objeto de nossa particular atenção. Ao longo dos anos em que esteve estreitamente relacionada com projetos nas áreas de saúde pública, ensino e pesquisa no país, a Fundação Rockefeller produziu, assim como permutou com o governo brasileiro, amplo material iconográfico relativo às suas áreas de interesse e de atuação. Por possuir escritórios no Brasil, esse material circulava entre os profissionais que ali trabalhavam e em muitos casos era remetido ao escritório central da instituição, em Nova York.

Esse circuito de produção e troca não se efetuava aleatoriamente, isto é, não se tratava apenas de troca de informações visuais ou de remessa de imagens sobre o país no qual os trabalhos vinham se concentrando. As fotografias eram peças importantes na lógica de funcionamento da Fundação Rockefeller e foram amplamente produzidas, acumuladas e sistematizadas por ela. Além das imagens produzidas pela equipe da fundação, eram colecionadas imagens enviadas pelo governo brasileiro apresentando as atividades e os serviços desenvolvidos nas áreas de medicina e saúde pública no país. Após sua produção, circulação e consumo, o destino dessas imagens, não raro, eram os arquivos da instituição nos Estados Unidos. Tal é a origem do que hoje encontramos no arquivo da Fundação Rockefeller.

A série de imagens sobre o Brasil conta com cerca de 2.490 registros iconográficos, em sua maioria, fotografias. Além destas existem, em 
quantidade reduzida, mapas, gráficos, negativos e desenhos. Esses registros estão distribuídos por 94 pastas $(\text { folders })^{3}$ que receberam classificação temática. A abrangência temporal da série corresponde ao período compreendido entre as décadas de 1910 (a partir de 1916) e 1960 (até cerca de 1963), refletindo assim o tempo de duração dos laços que uniram os interesses norte-americanos e brasileiros em uma causa comum. Como boa parte das coleções documentais, esta apresenta concentrações variadas de registros por temas específicos e períodos distintos, como veremos a seguir.

De forma geral, a série de imagens sobre o Brasil encontra-se subdividida em grandes temas, que ganham um código alfabético. ${ }^{4}$ Esses temas refletem as atividades da instituição responsável pela formação da coleção, a Fundação Rockefeller. Nesse sentido, eles não esgotam todos os assuntos possíveis nas áreas de medicina e saúde pública na história recente do Brasil, mas trazem informações substanciais sobre os estudos, os empreendimentos, os resultados de vários investimentos realizados naquelas áreas pelo governo brasileiro e que contaram com o apoio da fundação.

Existe um conjunto de 477 imagens dispostas em 26 pastas que não apresentam letras que identifiquem um conjunto temático, mas todas possuem em comum o fato de se referirem a instituições brasileiras de ensino e pesquisa em várias áreas, tais como agronomia, medicina veterinária, agricultura, medicina, biologia, zoologia, microbiologia, virologia, além de terem sido produzidas na década de 1950, mais precisamente em 1957. Muitas trazem a informação de que seriam usadas no Rockefeller Foundation Grant \& Aids, na verdade, um plano de custeio visando à formação de profissionais estrangeiros em instituições norte-americanas. A maioria dos registros é de autoria de Neil MacLellan, e a temática, apesar de apresentar variações, é recorrente: aspectos de fachadas de instituições brasileiras, construção de prédios, atividades internas, como pesquisas em laboratórios, atividades docentes, atividades em campo (como captura de mosquitos e sangria de doentes, no caso dos estudos em virologia).

Neste conjunto, seis pastas (ao todo 208 fotos) diferenciam-se do restante, pois trazem informações visuais sobre o período inicial de atuação da Fundação Rockefeller no Brasil. Embora de forma esparsa,

\footnotetext{
${ }^{3}$ As 94 pastas citadas constituem a série Brasil. Vale mencionar a existência de mais seis pastas que também possuem imagens (cerca de sessenta fotografias) sobre o país, embora pertencentes a outra série do fundo Fundação Rockefeller, a de número 100, relativa à virologia (virus studies).

${ }^{4}$ Os temas presentes na série Brasil são: O — Febre Amarela; I — Malária; H — Ancilostomíase (Hookworm); A — Ciências Médicas; C — Enfermagem; D — Ciências Naturais/Agricultura; L — Educação em Saúde Pública; V — Virologia. Dessa forma, o código relativo a uma pasta seria composto pelo número da série dentro do fundo, no caso, 305, seguido da letra que representa o tema tratado pelo conjunto, acrescido da palavra Brazil e outras informações referenciais, tais como local, data, assunto. Exemplo: 305 D — Brazil — Institute of Biology, Curitiba — Biological Laboratory, 1957.
} 
e apresentando uma pulverização de temas, essas imagens retratam os contatos da Comissão Rockefeller com a classe política brasileira em almoços e encontros, levantamento visual de regiões do país, com aspectos de vegetação, plantas, frutos, sementes, doentes etc.

Existe também nessas pastas conjuntos mais orgânicos de fotos produzidos com o intuito de 'reportagem visual' sobre os serviços de assistência médica existentes no Brasil relativos a várias doenças, como atesta o conjunto de imagens que provavelmente integravam um álbum da Inspetoria de Profilaxia da Lepra e Doenças Venéreas. ${ }^{5}$ Nesse caso, as imagens foram produzidas no Brasil e remetidas aos médicos da Fundação Rockefeller, provavelmente a pedido da própria equipe da fundação, para integrar algum relatório.

O conjunto ainda apresenta registros do estande da Junta Sanitária Internacional - International Health Board (IHB) - , que incluía uma seção de exibição das atividades da Missão Rockefeller no país durante a Exposição Internacional do Centenário da Independência do Brasil, em 1922, no Rio de Janeiro, mostrando suas atividades junto ao Departamento Nacional de Saúde Pública (DNSP), além da cobertura dos trabalhos realizados em Angra dos Reis (RJ) por ocasião da epidemia de febre tifóide, na década de 1930.

Quanto aos temas classificados na coleção, comecemos pelo de 'enfermagem', representado pela letra C, que conta com três pastas, com 93 fotografias, em sua maioria apresentando notável qualidade técnica e estética. Abrangendo o período de 1922 a 1930, o tema diz respeito às atividades das enfermeiras formadas pela Escola de Enfermagem Anna Nery, um empreendimento que teve a participação da Fundação Rockefeller.

Entre os assuntos retratados, destacam-se: enfermeiras em atuação na epidemia de febre tifóide no estado do Rio de Janeiro (Angra dos Reis) em 1934, ${ }^{6}$ atividades docentes e prático-profissionais da Escola

\footnotetext{
5 Trata-se de um conjunto de 136 fotografias coladas em cartão perfurado — produzidas no Brasil - documentando as atividades do serviço de profilaxia da lepra e doenças venéreas. As imagens vêm acompanhadas de legendas em português, datilografadas, e apresentam as fachadas e interiores de dispensários e clínicas. A abordagem do espaço interior das instituições revela as instalações internas e as atividades dos serviços, como aspectos da sala de espera, sala de exames e sala de curativos e injeções. O conjunto divide-se em: 1) dispensários e clínicas no Distrito Federal; 2) dispensários e clínicas na zona rural do Distrito Federal; 3) dispensários e clínicas em estados do Norte, Centro e Sul do país; 4) Serviço de Profilaxia das Forças Armadas; e 5) Conferência e exposição de propaganda e educação higiênica. Além das imagens, apresenta textos, gráficos e material impresso de propaganda, recursos que auxiliam a formar uma visão abrangente do serviço no país.

${ }^{6}$ Essas imagens em nada diferem do conjunto sobre a epidemia em Angra dos Reis descrito anteriormente e que integra a série de pastas sem classificação. Provavelmente foram produzidas na mesma ocasião, porém, quando da organização arquivística dada pela Fundação Rockefeller, foram separadas e inseridas no tema 'enfermagem', talvez por integrarem um relatório intitulado 'Groups of nurses from the Dona Anna Nery School of Nursisng who were assigned to work done to control in epidemic of typhoid fever at Angra dos Reis, RJ, 1934 (These photographs accompanied a report by Dr. Leal Ferreira who was in charge of the work transmitted with letter 4262, 3-20-34 from Fred L. Soper)'. As outras imagens não integravam qualquer relatório que lhes conferisse essa identidade. Talvez por essa razão não tenha havido uma correlação dos conteúdos entre os dois conjuntos.
} 
Anna Nery, reportagem visual das instalações da escola, vendo-se o prédio, instalações internas, homenagens, desfile em uniformes da profissão. ${ }^{7}$ Existe ainda um conjunto de fotos em forma de 'reportagem' sobre o Hospital São Sebastião (fachada e aspectos internos dos pavilhões), com ênfase especial no pavilhão de tuberculose, tornando digno de nota o treinamento recebido pelas estudantes da Escola Anna Nery para os casos de doenças contagiosas.

O tema 'ciências naturais/agricultura' (letra D) conta com 358 imagens distribuídas por 19 pastas em tudo semelhantes ao primeiro conjunto sem referência de letra. Nesse temário, contamos com imagens de instituições de ensino e pesquisa em áreas do conhecimento científico como biologia, medicina, química, genética, histologia, embriologia, física, fisiologia, veterinária, agricultura, nutrição, agronomia, climatologia, virologia, ecologia, biobotânica, ciências domésticas, bioquímica, biofísica, zoologia. As fotos apresentam aspectos de instalações internas e externas, encontro e visita de professores, atividades em laboratório de medicina nuclear, fotos microscópicas, turma do I Encontro LatinoAmericano de Metodologia de Radioisótopos. Algumas imagens trazem consigo a informação de que foram usadas em alguma edição do Annual Report, da Fundação Rockefeller. ${ }^{8}$ Os assuntos são bem diversos, como vimos, desde atividades de pesquisa stricto sensu - em laboratório -, até aspectos da construção da Cidade Universitária, na Ilha do Fundão, Rio de Janeiro.

Um outro grupo de 44 fotografias diz respeito ao tema 'ciências médicas' (letra A) e conta com três pastas referentes a instituições de ensino superior no Brasil, como as universidades de Minas Gerais e do Rio Grande do Sul. Elas não apresentam diferenças com relação às demais examinadas anteriormente (letra D e sem letra), mantendo o padrão de exibição de cenas de edificações dessas instituições, tanto internas quanto externas, além de registros das atividades desenvolvidas em ensino e pesquisa. O conjunto refere-se aos anos de 1961 e 1962, aproximadamente, e traz a referência de que as imagens foram utilizados no Annual Report da Fundação Rockefeller de 1964. Vale observar que em algumas fotos da universidade gaúcha consta o carimbo "UFRGSdivulgação", o que sugere a possibilidade de terem sido doadas ou até mesmo remetidas por essas instituições brasileiras para a Fundação Rockefeller, e não produzidas exclusivamente por ela.

\footnotetext{
${ }^{7}$ Essas fotos apresentam algumas autorias, como M. Dumiense (14 fotos), o mesmo autor da cobertura fotográfica dos trabalhos de enfermagem durante a epidemia de febre tifóide em Angra dos Reis, e Augusto Malta, presente com oito registros tirados em 1927 sobre as instalações do prédio onde funcionava a escola de Enfermagem Anna Nery, na avenida Rui Barbosa, onde até recentemente funcionou a Casa do Estudante da Universidade Federal do Rio de Janeiro (UFRJ).

8 The Rockefeller Foundation Annual Report é uma publicação anual cujo objetivo é prestar contas das atividades desenvolvidas pela Fundação Rockefeller em todo o mundo. Apresenta relatórios financeiros, administrativos e operacionais dos trabalhos em desenvolvimento nas suas várias juntas e divisões internas, sempre acompanhados de documentação fotográfica.
} 
A letra $\mathrm{H}$ é representativa do tema ancilostomíase e, apesar de contar com apenas duas pastas, possui cerca de oitenta registros divididos em pasta I (1916-18) e pasta II (1919-25). Trata-se de amplo e interessante conjunto de imagens relativas aos trabalhos empreendidos pela Rockefeller no combate àquela enfermidade. Este era o primeiro objetivo da instituição no Brasil, e, conseqüentemente, o primeiro tema de interesse, reforçado pela experiência que a fundação já possuía no trato com a doença, adquirida nos trabalhos travados no interior dos Estados Unidos no início do século XX.

Muitas fotografias apresentam-se coladas em cartões maiores com perfurações (o que sugere possíveis usos ou formas de colecionamento: poderiam pertencer a fichários produzidos pela administração da instituição, poderiam estar anexadas a relatórios etc.), acompanhadas por legendas datilografadas e/ou alguns comentários. Esses comentários fogem ao estilo de descrição mais objetiva apresentado pelas legendas e permitem uma apreensão da opinião pessoal do médico responsável pelo envio das imagens. Os principais assuntos retratados são: aspectos de laboratórios de pesquisa para o estudo da doença em várias cidades brasileiras, imagens de doentes, registros das melhorias sanitárias resultantes dos trabalhos empreendidos - como a construção de latrinas e tanques sépticos (esse tema concentra-se nos trabalhos desenvolvidos em Jacarepaguá, RJ, em 1920) e fotografias da inauguração oficial dos trabalhos de combate à doença no estado do Rio de Janeiro, em abril de 1917.

Nesse conjunto, vale ressaltar a existência de um subconjunto de 15 imagens, de autoria de Lewis Wendell Hackett, tiradas em 1921. Hackett era médico de prestígio da Fundação Rockefeller, representante da comissão sanitária que, entre 1916 e 1917, estabeleceu no Brasil o núcleo do que viria a ser o escritório regional da fundação no país, tornando-se seu primeiro dirigente. Além de médico e diretor associado da International Health Board no Brasil, era também um competente fotógrafo. Os inúmeros registros produzidos por ele durante sua trajetória na instituição estão reunidos na Lewis Hackett Collection, guardada no RAC, que conta com uma série de diários escritos de 1910 a 1962, além de correspondências e de uma série contendo fotos, negativos e slides arquivados em grupos de acordo com suas anotações.

O caso de Hackett é exemplar da dinâmica de produção de imagens característica da Fundação Rockefeller, que contava com sua própria equipe como autores das fotografias (e raramente com fotógrafos profissionais). Essa era uma atividade complementar e diretamente relacionada à produção dos registros que visavam relatar, descrever e observar aspectos variados das mais diversas atividades. Com sua visão 'interna' dos temas e paisagens dignos de nota para serem colecionados, as imagens ora revelam uma temática institucional/administrativa (a presença da instituição por meio da apresentação das edificações fachadas de laboratórios - e recursos humanos disponíveis - equipe 


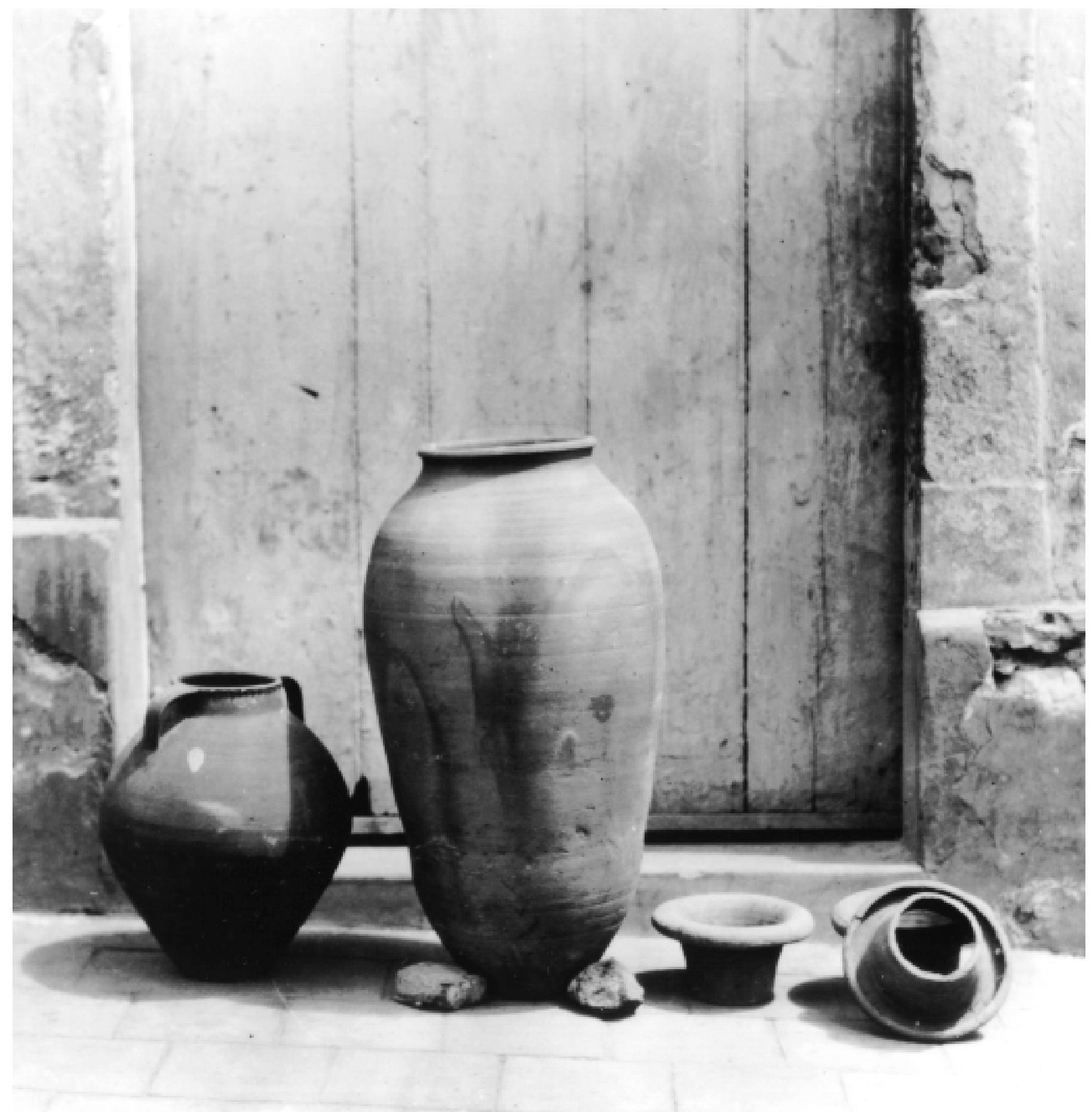

Para os médicos da Rockefeller, a fotografia tornava possível a descrição visual de um inventário dos hábitos e das condições de vida da população local. Ao longo de suas viagens pelo país, foram colhidas imagens como esta, que retrata as formas de armazenamento e saneamento da água, encontradas nas residências de cidades paraibanas. Ao centro, um jarro muito utilizado para armazenamento. À direita, um pequeno utensílio destinado à proteção de vasos com flores, e, à esquerda, um tipo de reservatório pequeno, também muito comum na região. 
Foto produzida por médicos da Rockefeller, no estado da Paraíba, provavelmente durante os anos 1920, e que, como tantas outras, cumpria a função de documentar as condições sanitárias e de saúde das populações brasileiras, tanto rurais quanto urbanas. Essas imagens eram muitas vezes utilizadas em relatórios de pesquisa que apresentavam um levantamento minucioso da região ou cidade objeto de interesse para possível intervenção da fundação. A foto tem a seguinte legenda original: "Uma maneira importante de auxiliar os trabalhos de distribuição de água para as casas são as conexões entre os diversos chafarizes. As estações públicas de abastecimento estão localizadas em vários pontos da cidade. Em uma cidade da Paraíba existem mais de 25 desses depósitos, distribuídos de acordo com a demanda da vizinhança. $O$ serviço funciona regularmente pela manhã e irregularmente à tarde. A água destas estações custa vinte réis por lata ou barril de cinco galões ... . Nas casas menores, duas latas suprem as necessidades de uma família por dia, perfazendo uma despesa insignificante. Uma boa quantidade desta água é transportada pela população sem qualquer desperdício."
Veículo utilizado pelo Serviço de Febre Amarela, do Departamento Nacional de Saúde Pública, para as atividades de fiscalização e combate ao mosquito Aedes aegypti

(Rio de Janeiro, maio de 1934). Foto: Voltaire de Alva.

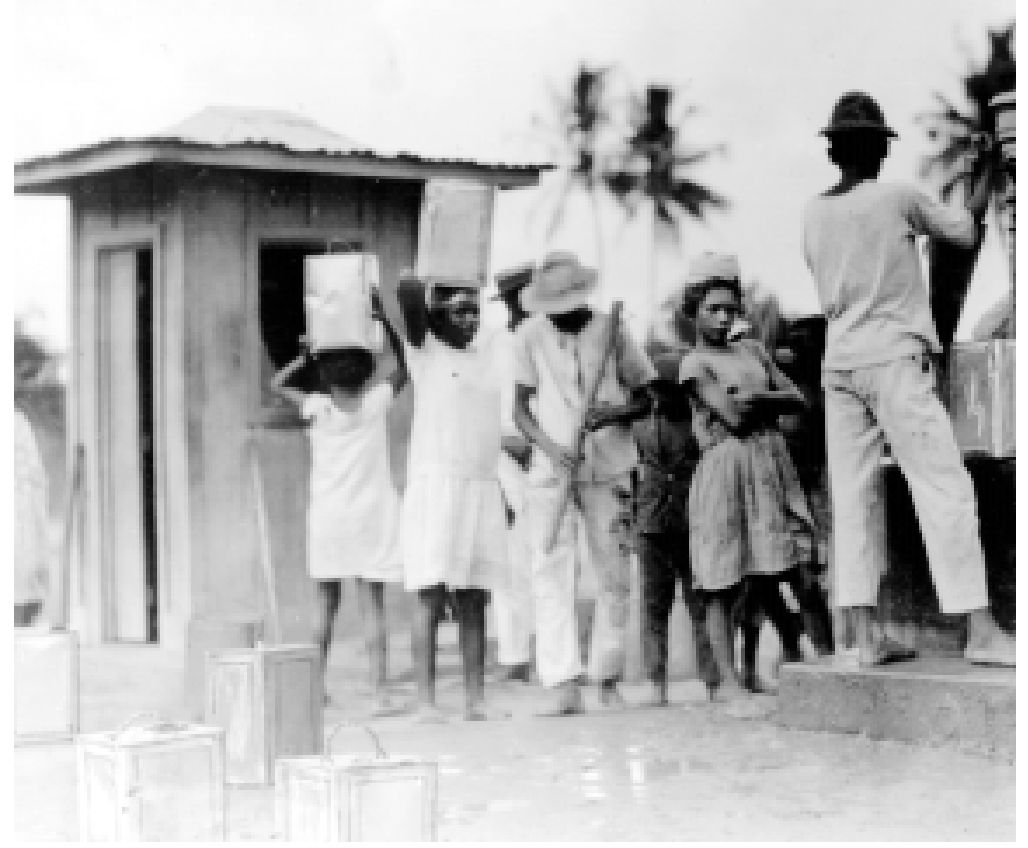




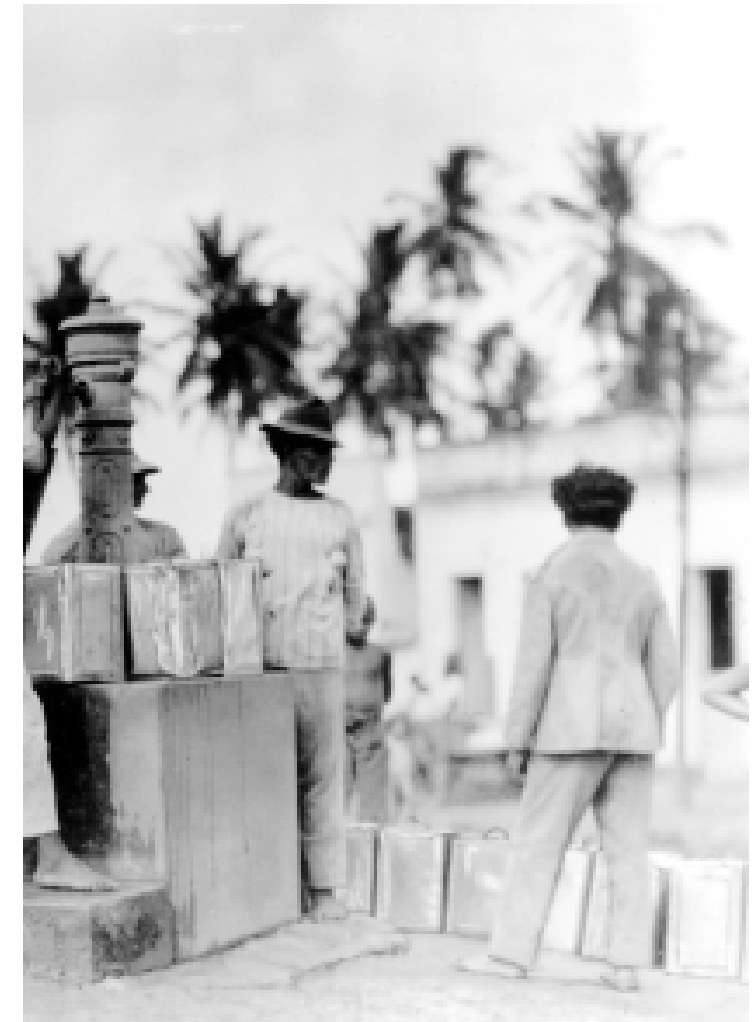

RETRATOS DO BRASIL

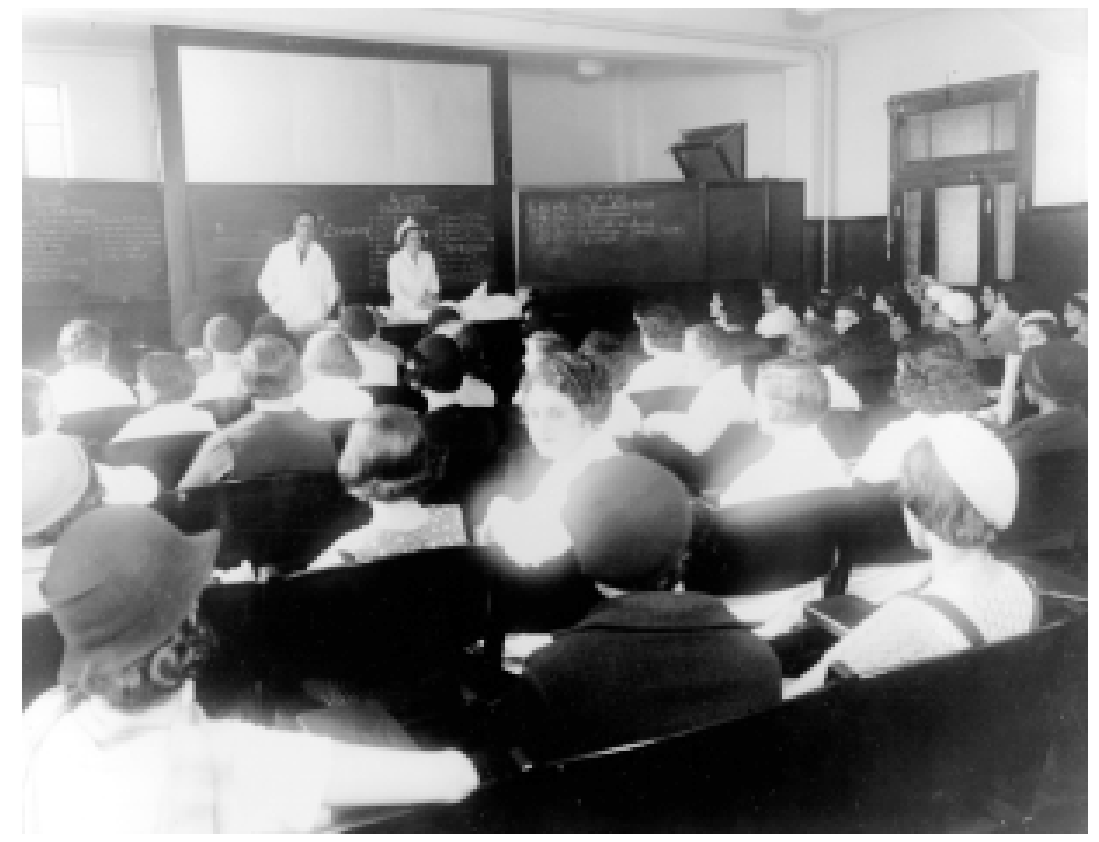

Curso para enfermeiras de guerra, que, juntamente com o curso de emergência para enfermeiras, foi ministrado durante a revolução de 1932, no Instituto de Higiene de São Paulo.
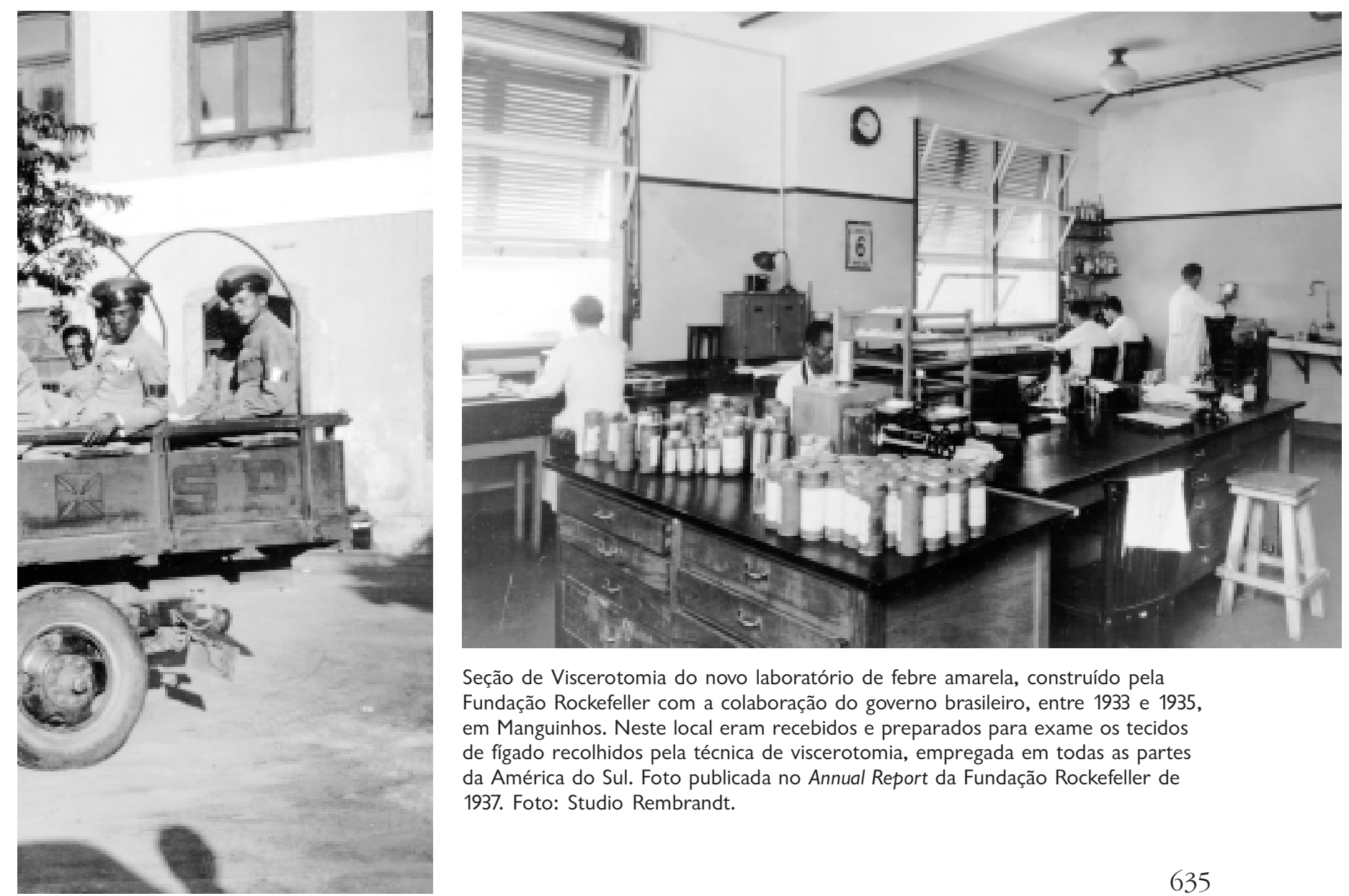

Seção de Viscerotomia do novo laboratório de febre amarela, construído pela

Fundação Rockefeller com a colaboração do governo brasileiro, entre 1933 e 1935, em Manguinhos. Neste local eram recebidos e preparados para exame os tecidos de fígado recolhidos pela técnica de viscerotomia, empregada em todas as partes da América do Sul. Foto publicada no Annual Report da Fundação Rockefeller de 1937. Foto: Studio Rembrandt. 


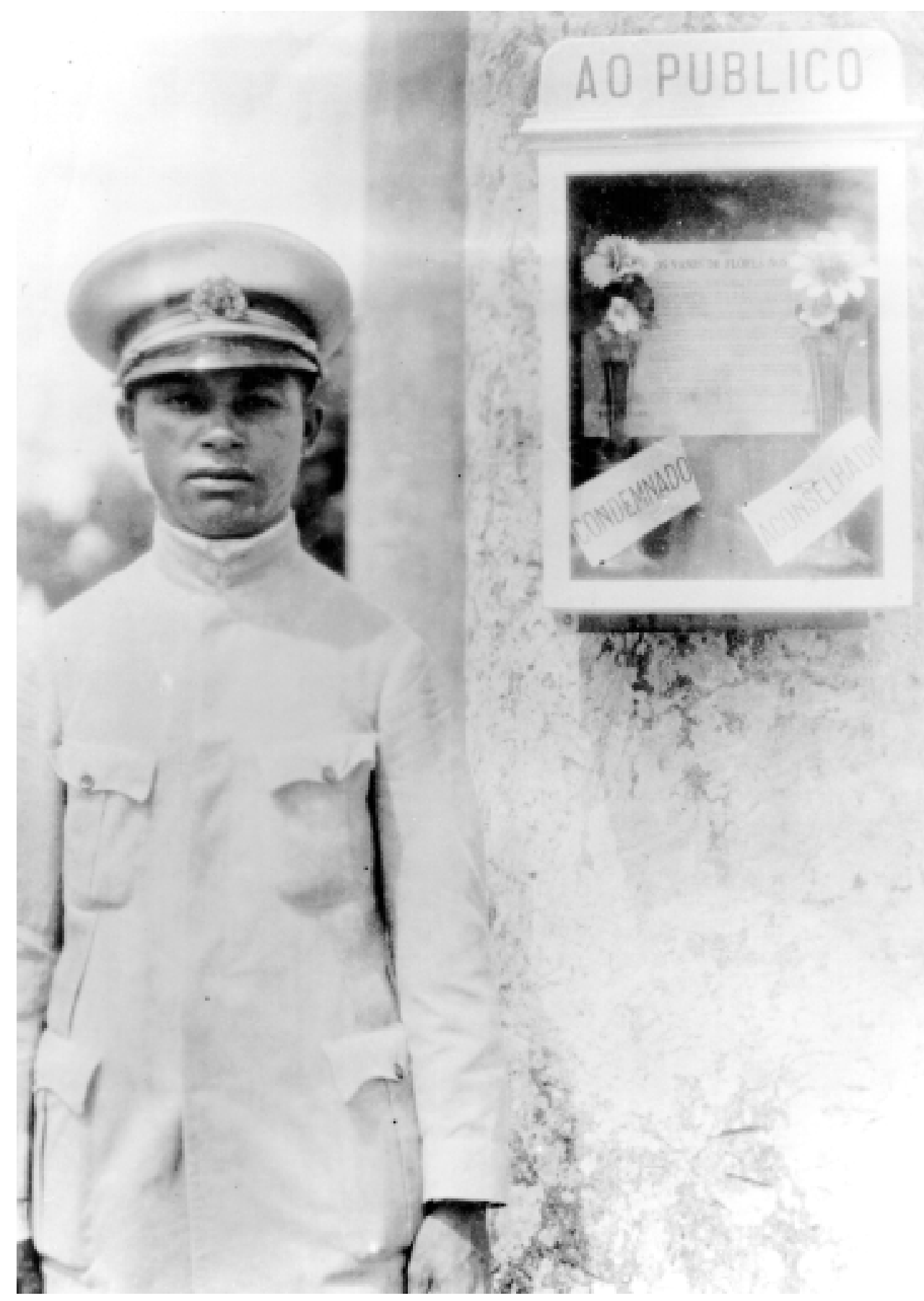

Cabine de exibição, instalada pelo Serviço de Febre Amarela nos cemitérios, com o objetivo de ensinar ao público o enchimento correto de vasos com terra úmida, e não com água (Cemitério Santo Amaro, Recife, PE, c. 1930).
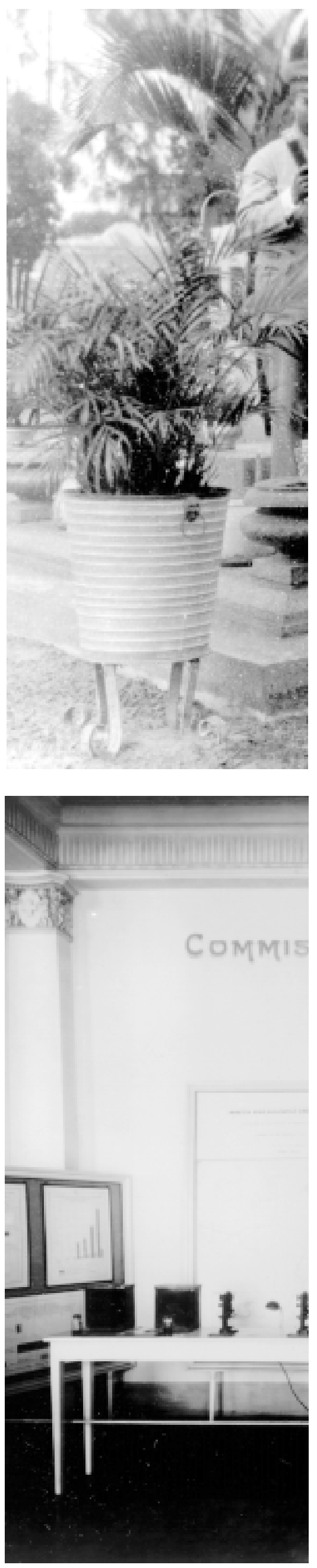


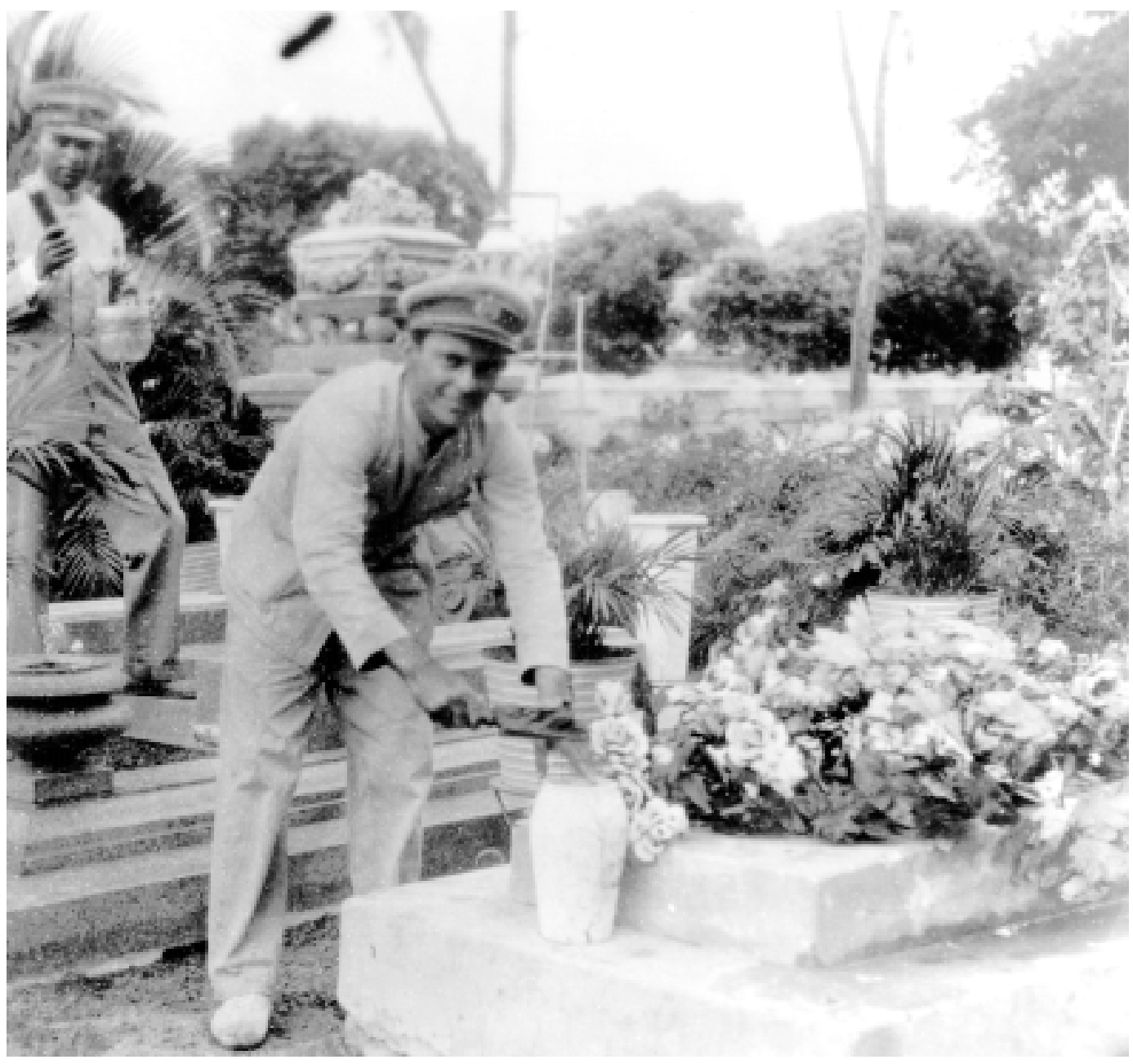

RETRATOS DO BRASIL

Guardas do

Serviço de Febre Amarela

examinam vasos de flores e enchemnos de areia para evitar a formação de novos focos de Aedes aegypti

(Cemitério Santo

Amaro, Recife, PE, c. 1930).

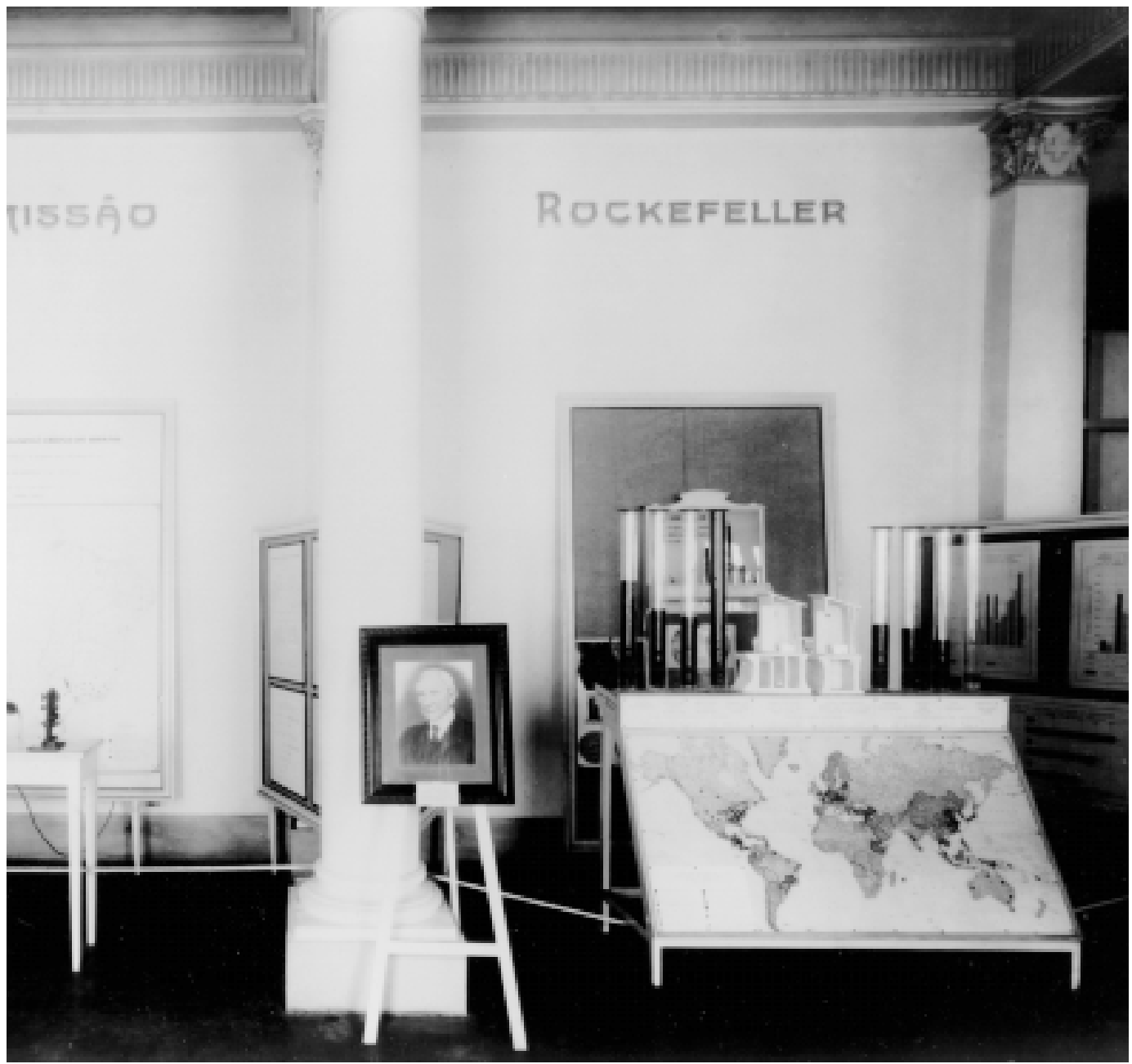

Exposição

Internacional

comemorativa do

Centenário da

Independência do

Brasil, realizada no

Rio de Janeiro em

setembro de 1922

Nela estava

exposto o estande

da International

Health Board

(IHB), com a

exibição de

aspectos dos

trabalhos

desenvolvidos pela

Comissão

Rockefeller no

país. 

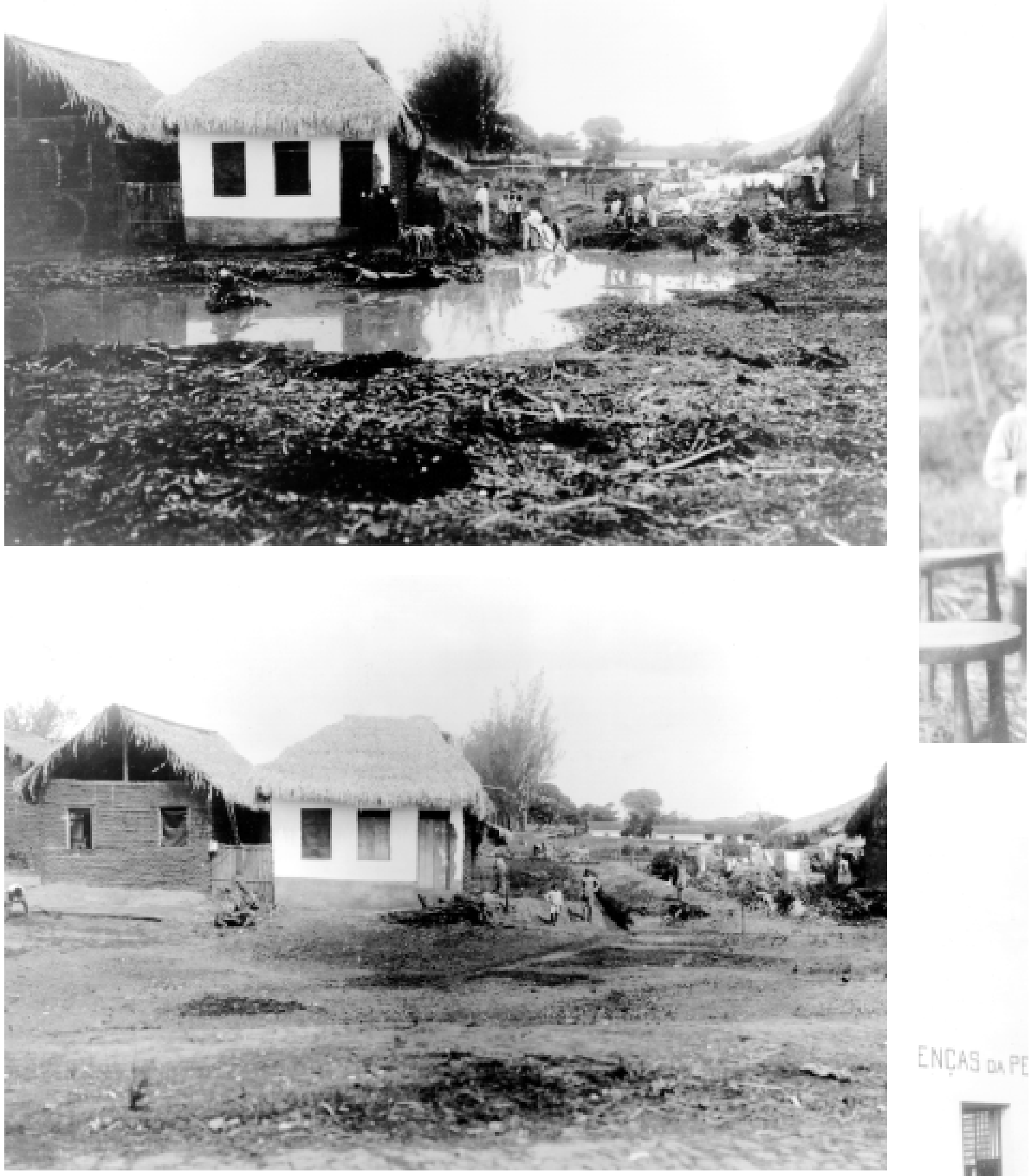

Dois aspectos dos trabalhos de drenagem de águas paradas em São Luís (MA), em janeiro de 1930.

Um exemplo da estratégia, muito utilizada pela fundação, de uso de imagens que funcionavam como 'antes' e 'depois' da intervenção da instituição, auxiliando na construção da idéia de progresso, invariavelmente ligada à sua performance.

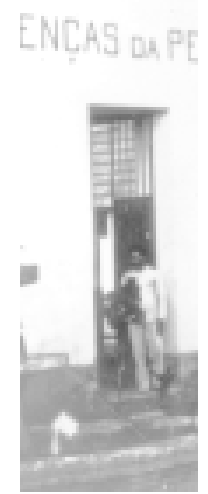




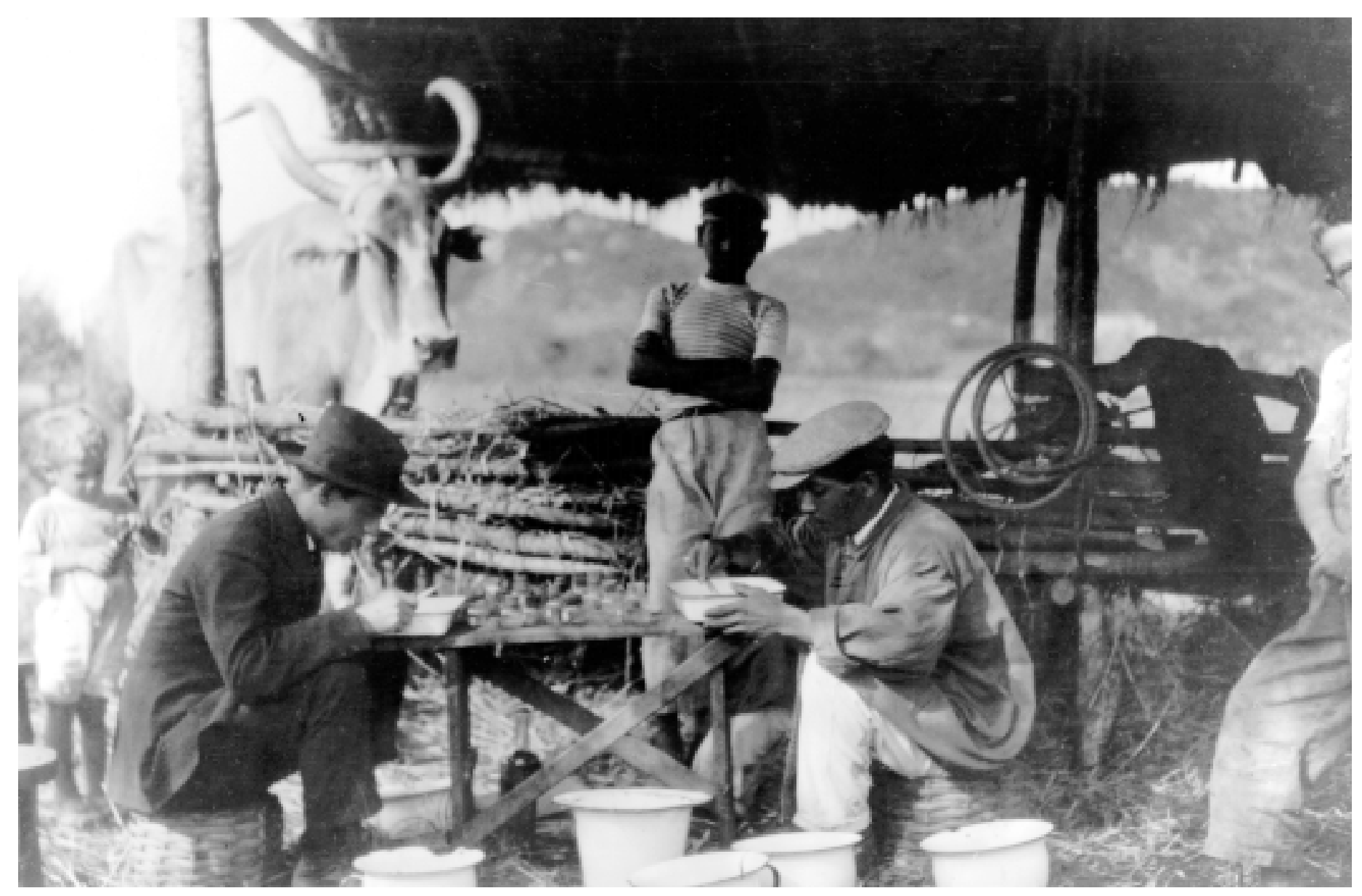

Contagem de ancilóstomos durante as pesquisas de campo sobre a ancilostomíase nos anos 1920. A legenda original diz: "Experimentos científicos cuidadosos podem ser realizados com sucesso em condições precárias."

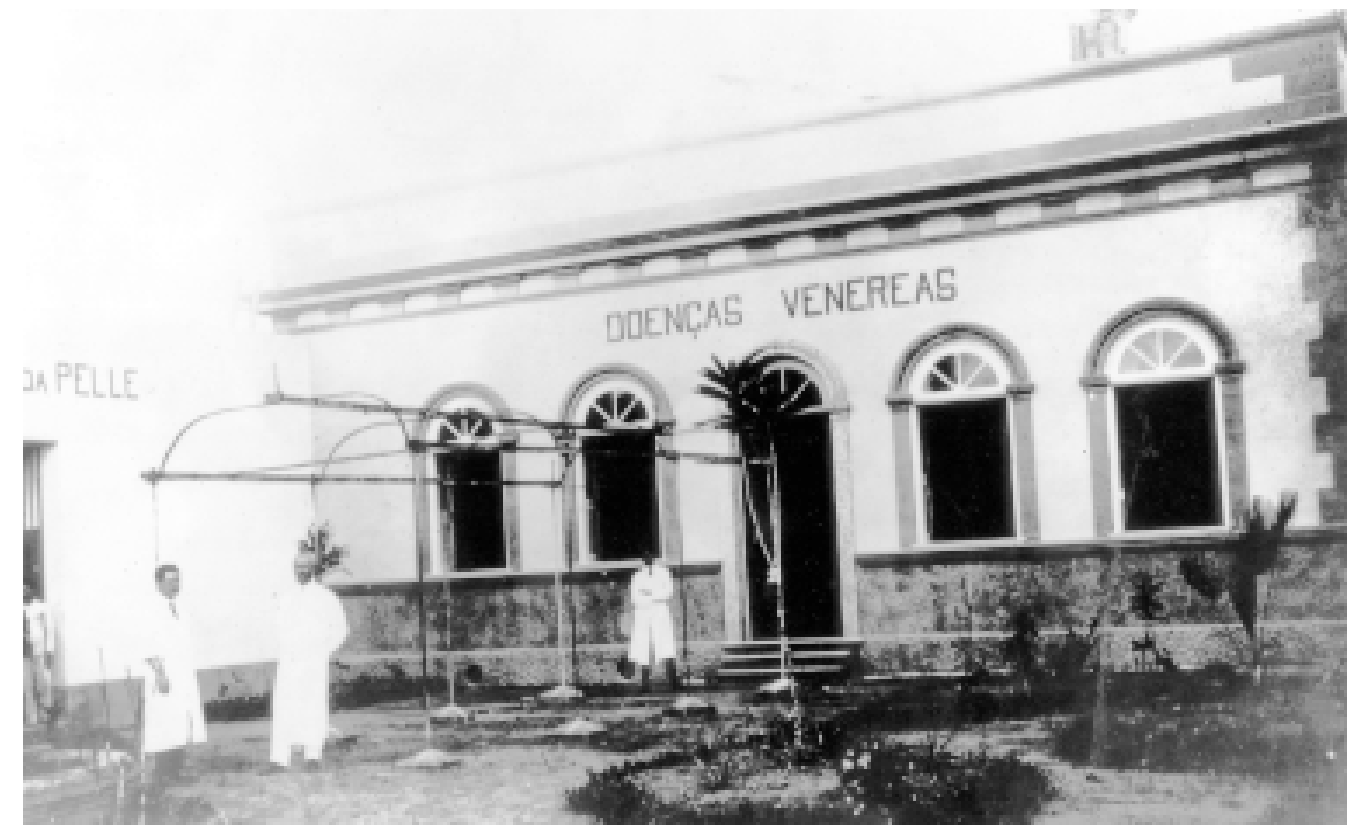

Fotografia produzida para integrar reportagem fotográfica sobre realizações do governo brasileiro na área da saúde pública. Os registros das edificações - clínicas, hospitais, sanatórios, dispensários etc -, eram abundantes nessas reportagens e funcionavam como testemunho da presença e da ação governamental na área. 


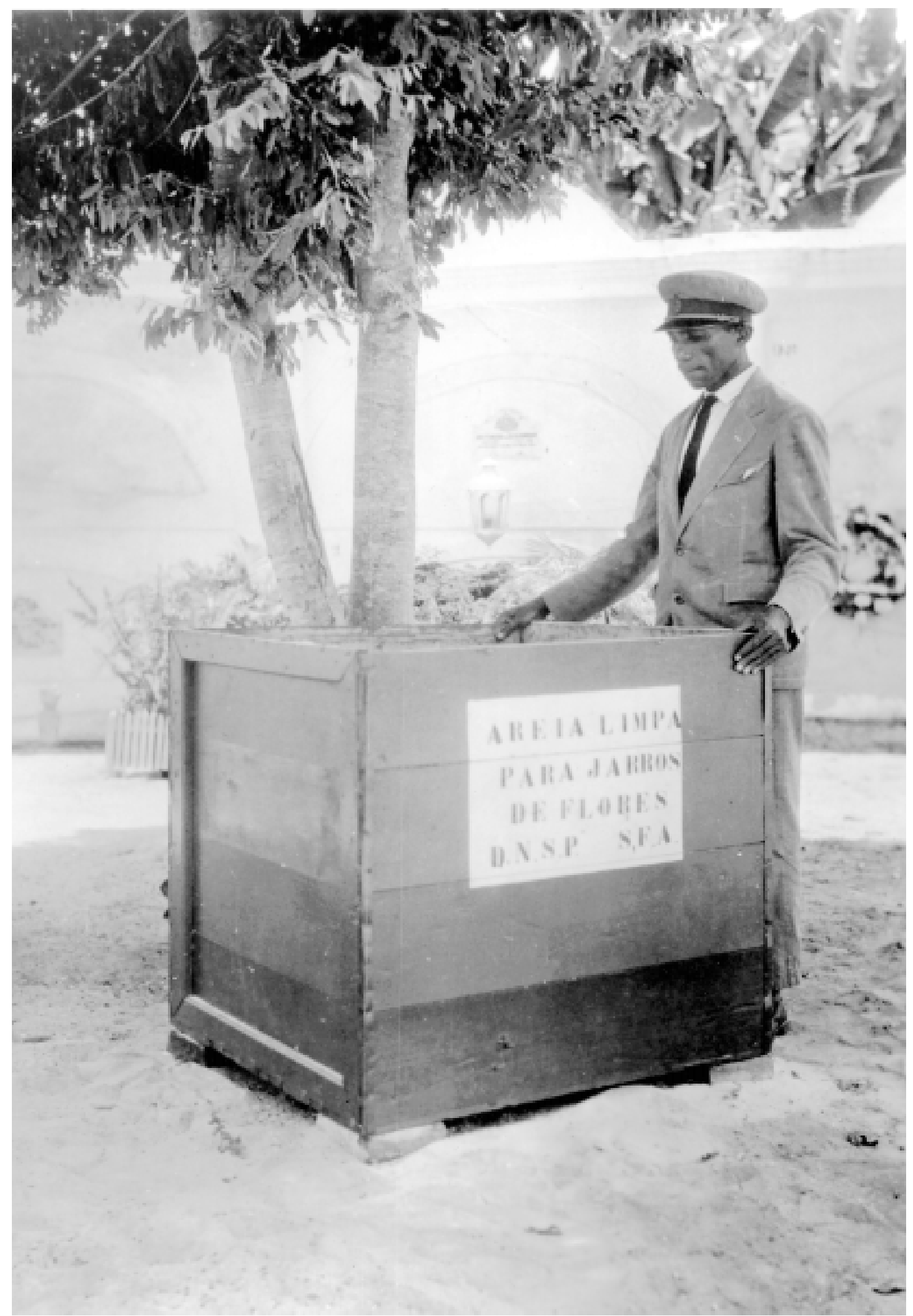

Um dos depósitos de areia limpa extraída da praia, localizado no cemitério para a conveniência das pessoas que freqüentavam o local. Esse recurso, oferecido pelo Serviço Nacional de Febre Amarela, visava a troca da água dos vasos pela areia, para evitar proliferação de mosquitos. Recife, 1930. 
dos postos de atendimento), ora funcionam como relatos quase etnográficos das condições de vida e costumes das populações locais (condições sanitárias - uso de privadas —, soluções encontradas pelos habitantes para abastecimento de água e despejo de detritos distribuição e venda de água dos poços centrais das pequenas localidades feita por crianças - levantamento visual dos tipos de moradia rurais e urbanas, utensílios domésticos para armazenagem de água, registros de costumes de valor negativo à visão sanitarista como o corte de um boi para a retirada de carne realizada às margens de um rio com cachorros em volta).

O tema ancilostomíase ainda nos permite tecer dois comentários, o primeiro relativo à presença de crianças nas imagens. Estas são muito focalizadas, mas numa dupla perspectiva. De um lado, estão presentes quando se trata de representar a população doente. De outro, enfatizam a idéia de educação sanitária, ou seja, representam a necessidade de se imprimir desde cedo no indivíduo noções de higiene e de disciplina estrita no cumprimento das tarefas de higiene, como a foto que mostra um grupo escolar com cada criança segurando um penico na mão.

O segundo comentário diz respeito à existência de imagens que apresentam uma família infestada pela doença em dois tempos distintos, antes e dois anos após a campanha intensiva, estratégia visual empregada em um procedimento chamado resurvey. Essa nova pesquisa, efetuada após a campanha sanitária, exibia imagens de dois momentos, um 'antes' e 'depois' dos procedimentos da instituição, buscando associar aos trabalhos efetuados um valor positivo. Isto sugere uma outra função reservada às imagens em uma campanha de saúde pública: a de 'comprovação de resultados'. Para os estudiosos da fotografia, valeria um aprofundamento dessas várias 'marcas' encontradas de forma aparentemente aleatória nos arquivos para a verificação dos recursos que a imagem fotográfica representava nos trabalhos da Rockefeller.

O segundo tema com maior incidência de imagens na coleção, malária, representado pela letra I, conta com quinhentos registros fotográficos e seis mapas distribuídos em 12 pastas e abarcando o período de 1920 a 1955. De maneira geral, podemos considerar dois momentos nas tomadas fotográficas sobre o tema malária. O primeiro refere-se às atividades efetuadas pela fundação nessa área anteriormente a 1930, quando ela atuou no planejamento e desenvolvimento de trabalhos em saúde na esfera municipal e/ou estadual. O segundo momento, na campanha de combate ao mosquito Anopheles gambiae, no Nordeste, sob a responsabilidade do Serviço de Malária do Nordeste e a direção da Fundação Rockefeller.

Nos anos 1920, as atividades de combate à malária, assim como à ancilostomíase, compreendiam, entre outras medidas, a profilaxia e o saneamento das áreas suscetíveis por meio da construção de diques para canalizar as águas paradas e a drenagem de rios e brejos, cenários propícios ao desenvolvimento de mosquitos. Dessa forma, constata-se 
a existência de imagens dessas atividades com a repetição da estratégia do 'antes' e 'depois', mostrando-se mais uma vez a situação inicial não satisfatória e o inegável melhoramento após a intervenção da instituição.

Ainda desse período são os levantamentos fotográficos sobre as condições sanitárias encontradas em várias localidades, que hoje nos permitem inventariar os tipos de fossas utilizadas, as formas de distribuição de água em pequenas localidades etc. Essas imagens acompanhavam os surveys, relatórios produzidos pela equipe da Rockefeller com o objetivo de apresentar um quadro detalhado de cada região em estudo, tendo em vista a intervenção futura da instituição, ou já em decorrência dos acordos de cooperação técnica firmados. Atualmente separadas de seus conjuntos originários, essas fotos apenas sugerem a missão para a qual foram produzidas. Mas um olhar mais cuidadoso sobre o acervo do RAC permite localizar muitos surveys completos, apresentando texto e imagem, e faz-se necessário o cotejo com a coleção de fotos.

O destaque é o levantamento das condições de higiene da população, realizado pelo fotógrafo J. T. Alves no bairro de Jacarepaguá, em 1920, e aspectos de várias regiões fluminenses nas quais foram feitas intervenções desse tipo (Magé, Teresópolis, Itambi etc.). Registros mais institucionais também estão presentes, como imagens da equipe em vários postos de saúde, dispensários em pequenas cidades, escolas e departamentos de higiene, no escritório central do IHB no Brasil, fachadas e instalações internas de diversos serviços de saúde e higiene, além de registros das atividades de inspeção de larvas realizada em laboratórios, com a ajuda de microscópios. A multiplicidade de instalações e serviços permite-nos formar a idéia de uma rede de instituições em diferentes localidades lidando com a mesma problemática sob dois pontos de vista, o da profilaxia e o da educação.

Das atividades do SMNE, em finais dos anos 1930, encontram-se muitos registros, apresentando qualidade técnica e estética notável, no formato de cartões-postais. Apresentam uma divisão temática similar ao conjunto pré-1930: de um lado, registros de atuação mais institucional com a presença de imagens dos escritórios, laboratórios etc.; de outro, aspectos vários das regiões em foco (no caso, o estado do Ceará), como costumes, atividades de subsistência das populações (pesca, jangadeiros), os tipos regionais (lavadeiras, rendeiras) e o meio ambiente (praias, palmeirais, coqueirais etc.). Vale observar a ausência, nesse conjunto, dos personagens do SMNE, apesar da presença de imagens que documentam as obras em andamento (construção de diques de irrigação) ou alguns serviços (como a desinfecção de automóveis).

Existe um conjunto de cópias-contato fotográficas, reunidas ao lado de gráficos e mapas, com a referência de que teriam sido utilizadas em artigos científicos publicados por membros da equipe da Rockefeller no período, como R. C. Shannon e G. C. Andrade, Fred L. Soper ou B. Wilson. Nesses registros, esses médicos apresentavam seus estudos 
sobre o Anopheles gambiae no Brasil ou sobre observações acerca da estação da seca no Nordeste. Por último, um álbum intitulado Rockefeller Foundation - International Health Board — field studies of malaria in Brazil reúne 125 fotos e quatro mapas, além de imagens provenientes de fotogramas de um filme cinematográfico acerca do uso de verdeparis como eliminador do mosquito e sobre o serviço de drenagem para combate ao Anopheles.

Por último, o tema febre amarela (letra $\mathrm{O}$ ) — que concentra o maior número de imagens na coleção, 655 fotografias dispersas entre 19 pastas - coincide com a área de atuação que mais esforço e mais tempo demandou do empreendimento da instituição no Brasil. Em linhas gerais, há uma divisão temática entre assuntos retratados no interior dos laboratórios de pesquisa da doença e de produção da vacina, por um lado, e aqueles relativos às diversas atividades que integravam as pesquisas epidemiológicas promovidas em campo, por outro, este último com maior concentração de imagens.

Seguindo esses marcos, as atividades laboratoriais estão representadas iconograficamente na coleção, pela presença de reportagem sobre o laboratório mandado construir pela Fundação Rockefeller no campus de Manguinhos, para sediar as pesquisas e a produção da vacina. Nela são mostradas desde as instalações internas e externas da edificação e aspectos gerais das atividades desenvolvidas nas suas várias seções, até a imagem do 'produto final', no caso o 'kit vacina', que incluía os elementos necessários à vacinação em campo (a vacina acondicionada em um recipiente com isolamento térmico, seringas, balanças, fogareiro para desinfecção de agulhas etc.). Esta imagem simbolizava o resultado dos empreendimentos, ao mesmo tempo que desempenhava a função de atestar o cumprimento dos objetivos a que se destinava toda a mobilização institucional.

Vale observar que as fotos de vacinação propriamente dita também nos remetem ao universo do laboratório, de onde são provenientes, e ao universo do trabalho em campo, para onde era destinada a vacina produzida para os testes, como sugerem as imagens feitas durante um dia de vacinação em uma fazenda de café em Minas Gerais, na década de 1930. O tema vacina, portanto, situa-se em uma zona intermediária de interpenetração dos universos de atuação de médicos e cientistas nos trabalhos da Rockefeller, o laboratório e o campo.

A coleção traz ainda registros dos primórdios da atuação da instituição, com ênfase nas atividades de combate a focos do mosquito Aedes $a e g y p t i$, quando caixas-d'água e vasos que serviam como reservatórios de água e locais potenciais de criação de focos eram alvo de intervenção. Nesse esforço, foram amplamente documentados os costumes da população em diversas localidades com relação ao abastecimento e à reserva doméstica de água e as estratégias adotadas pelo Serviço de Febre Amarela, de acordo com o que havia sido determinado pela Rockefeller para combater os focos do mosquito. Entre as tarefas 
impostas, destaca-se a substituição da água armazenada nos vasos de flores localizados nos cemitérios por areia, que era inclusive fornecida pelo serviço e encontrava-se disponível em local estabelecido no interior dos cemitérios. Quanto à equipe envolvida nos trabalhos, cumpre registrar a existência de imagens do laboratório em Salvador (BA), o primeiro a abrigar a Fundação Rockefeller no país e sede da IHB, com destaque para a presença de Hideyo Noguchi e seus auxiliares.

Um último comentário diz respeito a um costume dos serviços nacionais e da própria Rockefeller: a exibição de aspectos dos trabalhos realizados por meio de exposições organizadas pelo governo brasileiro, que, de forma geral, expunha, como em uma vitrina, elementos considerados notáveis em termos de obras realizadas, utilizando um amplo leque de suportes de comunicação visual, como fotos, cartazes, objetos etc. Dessa forma, produzia-se uma espécie de 'prestação de contas' pública, ao mesmo tempo que isso contribuía para a divulgação e a propaganda das iniciativas governamentais.

Destacam-se na coleção aspectos da exposição do Serviço de Febre Amarela na Feira Internacional de Amostras, realizada no Rio de Janeiro, em 1936. O circuito de exibição de imagens dos trabalhos não raro eram os grandes eventos, como feiras e exposições, mas também efetuava-se cotidianamente, por meio da produção e circulação de relatórios, estudos, artigos e outros tipos de documentos de trabalho que eram consumidos por toda a equipe da Rockefeller, tanto no Brasil quanto nos Estados Unidos. Esses trabalhos podiam ser encaminhados por qualquer um dos médicos e cientistas atuantes, como resultado de uma pesquisa em uma região do país, de um trabalho científico publicado ou mesmo como anexo a uma correspondência oficial.

\section{O Brasil na Rockefeller e a Rockefeller no Brasil: acervos complementares}

Cabe observar que, ao mesmo tempo que se acumulava uma documentação sobre o Brasil nos Estados Unidos, outro arquivo vinha sendo formado no interior do laboratório de produção da vacina da febre amarela, em Manguinhos (Fiocruz). Integrado em sua maioria por cópias-contato - cópias não ampliadas de negativos fotográficos esse arquivo de imagens se conectava com todo o serviço efetuado no país, desde as pesquisas epidemiológicas, passando pelas técnicas de laboratório para diagnóstico patológico e sorológico da doença, até o registro da produção da vacina. Hoje faz parte do acervo da Casa de Oswaldo Cruz/Fiocruz, como foi mencionado.

Apesar de não tratada aqui, a menção a essa documentação é importante no sentido de apontar que, dessa longa parceria entre brasileiros e norte-americanos visando ao conhecimento e ao combate de endemias no Brasil, uma não menos extensa documentação foi produzida e/ou acumulada pelas personagens envolvidas. Pelas 
Agradeço ao Rockefeller Archive Center (RAC), na pessoa de seu diretor, Darwin Stapleton, o convite e a concessão de bolsa para a realização da pesquisa, em maio de 2000 . dinâmicas pessoais e institucionais características dessa trajetória, essa documentação encontra-se hoje dividida entre uma instituição arquivística norte-americana (Rockefeller Archive Center) e uma brasileira (Casa de Oswaldo Cruz /Fiocruz).

Aqui, como lá, podemos conferir temáticas semelhantes, os mesmos fotógrafos, por vezes até as mesmas imagens, mas os dois conjuntos, no todo, são bem diferentes. Em cada caso, podemos perceber lógicas de acumulação distintas, resultantes de funções diversificadas dadas às fotografias na economia interna das instituições envolvidas. Como fontes para o estudo da história da participação da Fundação Rockefeller nos trabalhos brasileiros de pesquisa e combate à febre amarela e à malária, as coleções devem ser consideradas complementares, e, nesse sentido, precisam ser entendidas a partir de uma visão de dentro do arquivo, da história de sua produção e acumulação. Dessa forma, é possível explorar o que de diverso existe na aparente semelhança, tornando mais rica uma abordagem daquela história por meio das suas imagens. 